\title{
Comparison between two gas turbine solutions to increase combined power plant efficiency
}

\author{
Carlo Carcasci*, Bruno Facchini \\ Dipartimento di Energetica "S. Stecco”, University of Florence, Via Santa Marta, 350139 Florence, Italy
}

Received 18 February 1999; accepted 2 September 1999

\begin{abstract}
Significant research efforts are currently centered on developing advanced gas turbine systems for electric power generation applications. Gas-steam combined cycles are often used to obtain a high efficiency power plant. Two innovative gas turbine technologies have recently been proposed for combined cycle applications. Two gas-steam combined cycles using thermodynamic analysis are presented: a combined cycle with three pressure levels with reheat heat recovery boiler is used with two different gas turbine technologies (high pressure ratio and reheat against " $\mathrm{H}$ " technology). This analysis constitutes a comparison not only between two different constructive solutions but also between two different gas turbine (GT) techniques (reheat and GT steam cooling) and technologies (a consolidated and an advanced gas turbine technology) applied to a combined cycle. (C) 2000 Elsevier Science Ltd. All rights reserved.
\end{abstract}

Keywords: Combined cycle; Gas turbine; Reheat; Steam cooling blade; Heat recovery steam generator

\section{Introduction}

The evolution of energy conversion in power plants based on fossil fuel has been considerable in the last 20 years. Starting with some simple considerations on the efficiency limitations of gas turbine cycles, traditional steam power plants have been supplanted and combined with a gas turbine plant. The main, considerable losses in a simple turbogas plant

\footnotetext{
* Corresponding author. Tel. + 39-055-4796235/336; fax: + 39-055-4796342.

E-mail addresses: carca@brun.de.unifi.it (C. Carcasci), bruno@brun.de.unifi.it (B. Facchini).
} 


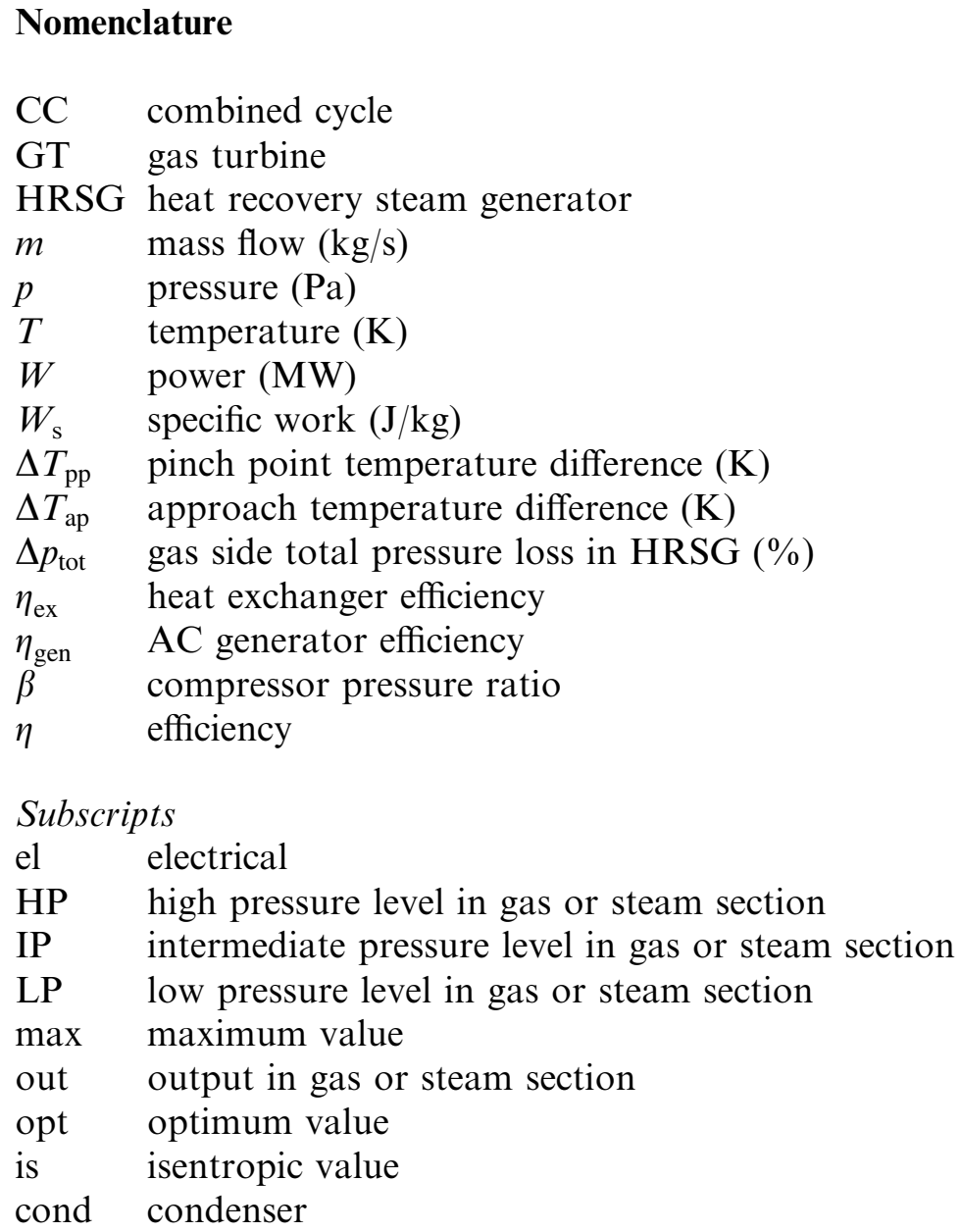

are due to the heat exchange from and to the exterior. The first source of loss is as low as the cycle maximum temperature is high and is, thus, connected with the development of materials and cooling techniques; this aspect represents the main development line of the gas turbine engine and is influenced by the increase of specific power generally required in aero-propulsion applications and by the increased efficiency needed to win over the heavy duty power plant market. Moreover, these efficiency increases are not sufficient to exceed those of traditional steam power plants, and so, it becomes indispensable to limit the second kind of loss. Consequently, a decrease of the temperature at which gases are released from the stack is required. The most wide spread solution for this has been, up to now, the adoption of steam cycles combined with gas ones: this kind of solution allows conversion of the thermal energy of the turbine exhaust gasses into mechanical work, obtaining the so-called gas-steam combined cycles (CC). In conclusion, the best solution is represented by a compromise between the gas and steam cycles. 
Before showing the results obtained by the simulation, the main features of the two machines considered are shown. First of all we will point out the principal consequences of the introduction of reheat. Later we will consider " $\mathrm{H}$ " technology, the heat recovery steam generator (HRSG) and finally we will present the main characteristics of the two turbines with reference to constructors' data.

Fig. 1 shows the thermodynamic cycle of the two gas turbine solutions.

\subsection{Reheat}

In the simple Joule cycle, the practice of reheat increases the specific work but at the same time, reduces efficiency. This loss is due to two conflicting causes:

- Increase of average temperature of heat supply

- Increase of average temperature of heat rejection

The only commercial heavy duty gas turbine using reheat is GT24/26; the partial expansion ratio was chosen in order that these two effects almost neutralise each other. Thus, the GT24/ 26 net efficiency of the cycle with reheat is less than $1 \%$ lower than that of the cycle without reheat.

Moreover, in this case, a less relevant maximum temperature increment is necessary to generate the required exhaust temperature, thus, a traditional cooling system technology is necessary. In any case, the increase of temperature of the exhaust gases has very beneficial

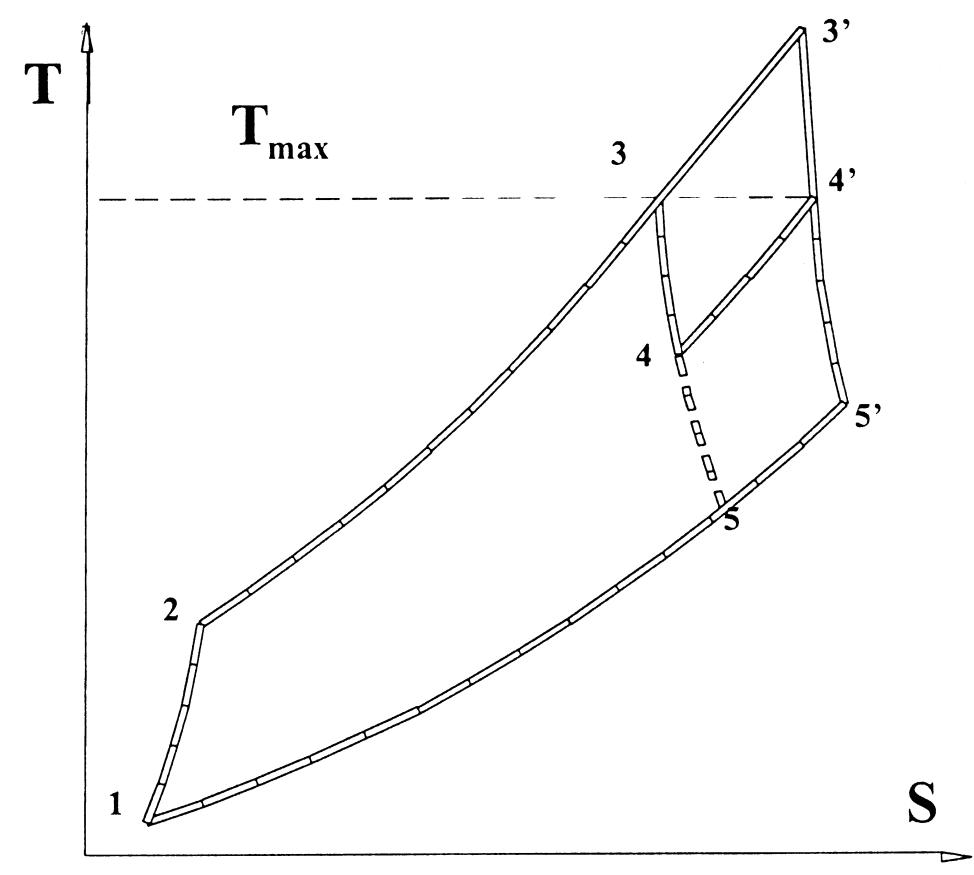

Fig. 1. Joule cycle with reheat and with a higher maximum temperature. 
effects on the efficiency of the bottomer steam cycle in the case of combined cycle power plant operation. In order to achieve better use of the heat associated with the exhaust gases, these must enter the HRSG at about $870-900 \mathrm{~K}$. The reheat exhaust gas stream can be obtained at these temperatures by simply controlling the pressure at which reheat takes place. The effects of GT reheat on the total efficiency of combined power plants can be quantified in a certain number of percentage units $(2-3 \%)$.

\section{2. " $H$ " technology}

The distinguishing feature of the " $\mathrm{H}$ " combined cycle system with a steam cooling solution is the flow of a steam coolant stream from the steam cycle to the gas turbine.

Comparing the " $F$ " and the " $\mathrm{H}$ " gas turbine technologies involves the following thermodynamic consequences:

- the first nozzle total $\Delta T$ of the gas turbine is drastically reduced, from about $300 \mathrm{~F}(160 \mathrm{~K})$ to about $90 \mathrm{~F}(50 \mathrm{~K})$, which means higher turbine inlet temperature with no relevant increase in combustion temperature and, consequently, low $\mathrm{NO}_{x}$ emissions [6];

- the quantity of air bled from the compressor for cooling is strongly reduced and can be bled at low pressure, so the compression work necessary to compress the cooling flow is strongly reduced;

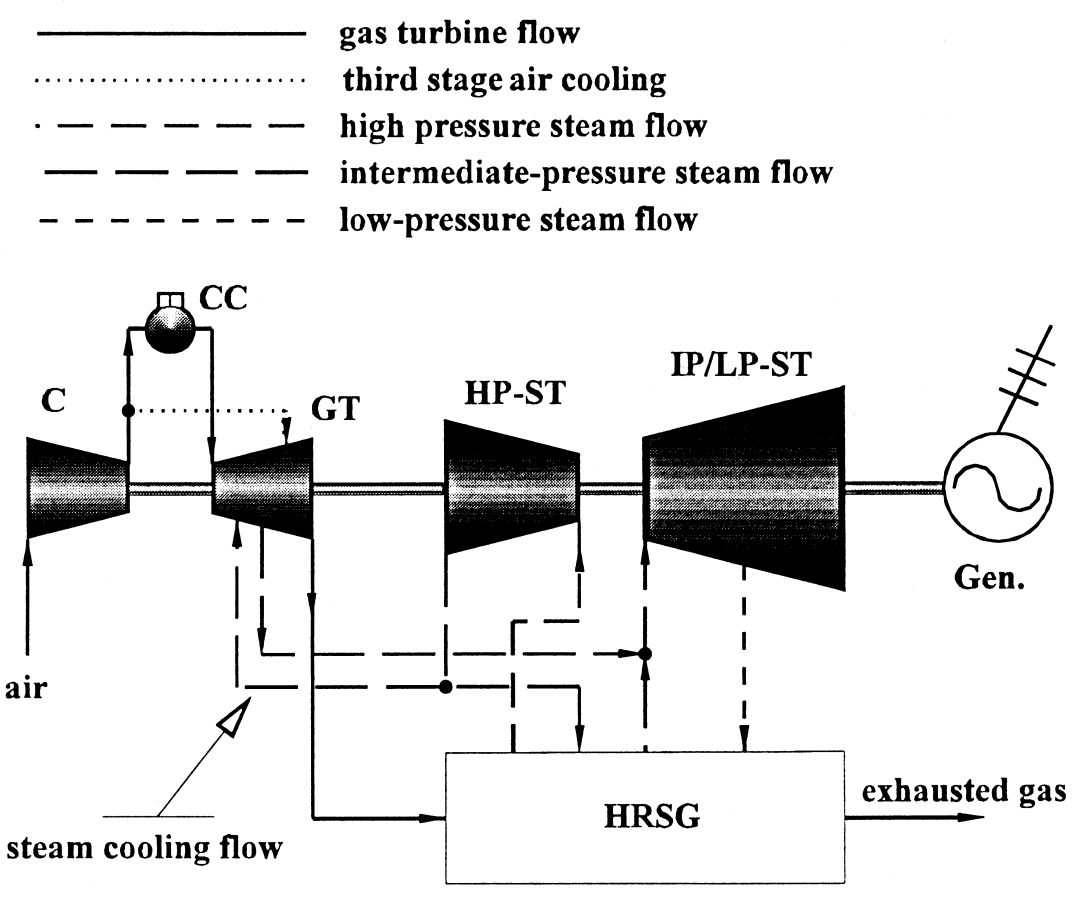

Fig. 2. Combined cycle scheme. 
- the heat withdrawn from the first two cooled stages of the gas turbine is completely recovered into the steam cycle.

The higher turbine inlet temperature yields a triple benefit:

increased gas cycle efficiency - that is, lower fuel consumption increased specific work - reduced capital cost increased exhaust gas temperature - improved performance of steam bottoming cycle

The scheme of the combined cycle is described in Figs. 2 and 3 (the latter describing the HRSG scheme for " $H$ " technology).

The high pressure steam from the HRSG is expanded through the high pressure section of the steam turbine. The exhaust steam from this turbine section is then split: one part is returned to the HRSG for reheating; the other is used for cooling the hot section of the gas turbine. After cooling the stationary and rotary hot components, the steam reaches, in practice, the reheat temperature. It is then mixed with the reheated steam coming from the HRSG and introduced into the intermediate pressure steam turbine section for expansion.

\subsubsection{Heat recovery steam generator}

For both the gas turbines considered, a three pressure level heat recovery steam generator was chosen to limit the destruction of exergy during the heat transfer process in the HRSG. This solution is commonly encountered in bottoming steam plants coupled with " $\mathrm{F}$ " class gas

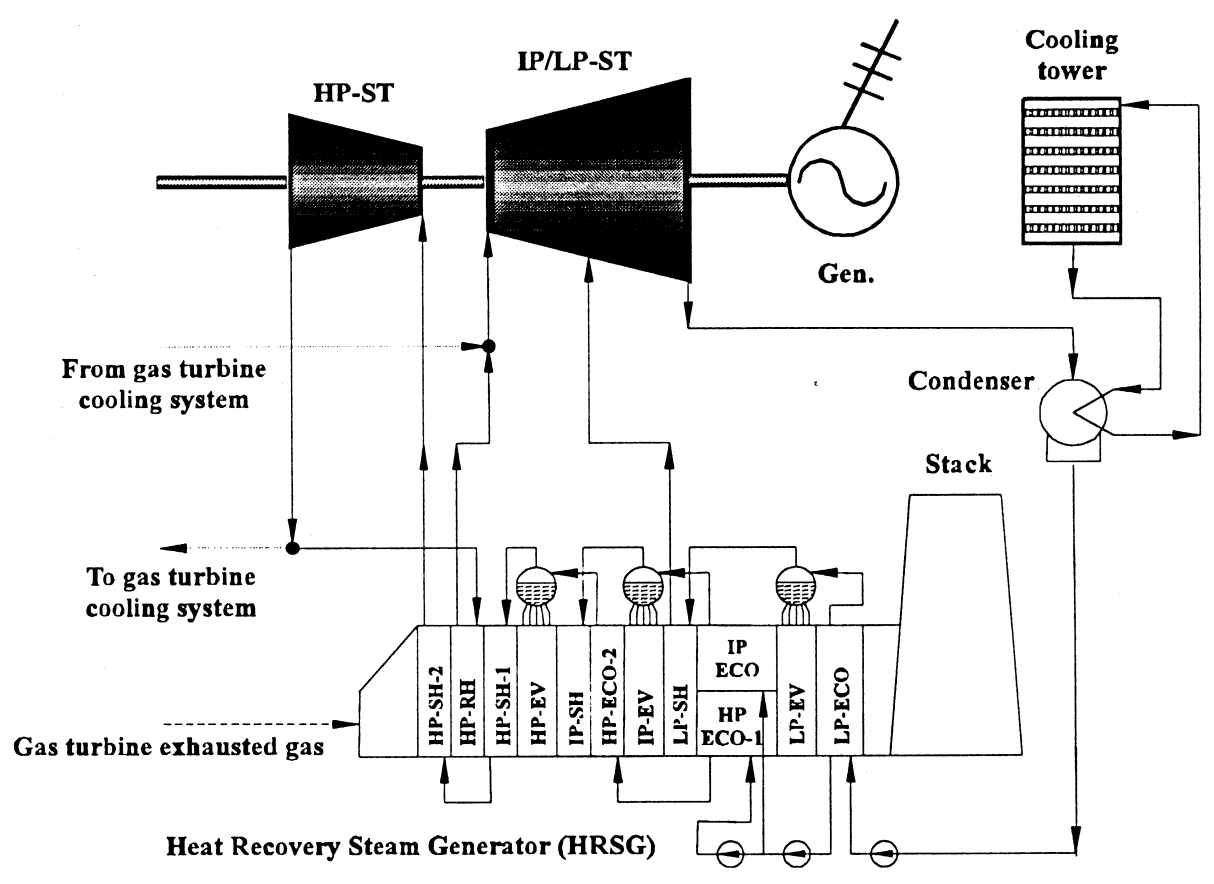

Fig. 3. Steam section scheme. 
turbines, because it allows high quality heat exchange performance and a full exploitation of the relevant gas turbine exhaust temperature.

\subsection{2. $M S 9001 \mathrm{H}$}

The MS9001H, manufactured by General Electric, combines a heavy duty gas and a steam turbine on the same shaft. In order to optimise efficiency and specific work, a $1700 \mathrm{~K}(2600 \mathrm{~F})$ firing temperature and a pressure ratio increase (with respect to " $F$ " class) were adopted. The Dry Low $\mathrm{NO}_{\mathrm{X}}(\mathrm{DLN})$ combustion system, now in service across the product line, was adapted to the "H" gas turbine [6].

In particular, the cooling system of the combustion turbine consists of:

first two stages steam closed cycle cooling system

third stage air cooling system (the cooling flow is taken from the compressor delivery and then re-mixed to the main flow after cooling of the GT stator)

fourth stage uncooled

\subsubsection{GT24/26}

The GT24/26, manufactured by ABB, is a large size (241 MW) heavy duty gas turbine [1,2]. This engine, with the distinguishing feature of an efficient reheat section, is particularly suited for combined cycles. Although a lower firing temperature is used (about $1500 \mathrm{~K}$ ) compared with the MS9001H, the compression ratio is relatively high $(30: 1)$.

The basic thermodynamic parameters of the two plants are shown in Table 1. The data concerning the GT26 are based on a real plant, while those of the LM9001H are projections from prototype scale testing or simulations. Experience teaches that these data can often be optimistic and presented by the turbine manufacturer in order to attract market attention to new products.

Table 1

Basic thermodynamic parameters of the plants

\begin{tabular}{lll}
\hline & GT26 & MS9001H \\
\hline Firing temperature class (K) & 1508 & 1700 \\
Air flow (kg/s) & 549 & 685 \\
Pressure ratio & 30 & 23 \\
Gas temperature at the entrance of the HRSG (K) & 883 & 885 \\
Supplementary firing temperature (K) & 1508 & - \\
Gas cycle power (MW) & 241 & - \\
Gas cycle efficiency (\%) & 38.2 & - \\
Combined cycle power (MW) & 366.6 & 480 \\
Combined cycle efficiency (\%) & 57.5 & 60 \\
\hline
\end{tabular}




\section{Simulation}

The simulations were performed with the use of a modular code developed by the authors [3-5]. The program facilitates the study of any power plant, whatever its configuration, without having to write a specific program for it. The models employed to describe the various elements can be of a different nature, ranging from essentially thermodynamic ones, like heat exchangers, to one-dimensional models used to describe turbines and compressors in design and off design conditions.

In this study, only thermodynamic analysis is considered.

\subsection{Hypotheses of the simulation}

The main hypotheses are separately stated for each plant component in the following sections.

\subsubsection{Heat recovery steam generator ( $H R S G$ )}

For both solutions considered in this study, the three pressure level heat recovery steam generator (HRSG) was simulated using the same values of the basic thermodynamic parameters. The values of these parameters are those commonly encountered by gas-steam combined cycles. However, we would like to state that they are not necessarily those which optimise the performance of the two reference plants. On the other hand, choosing the same values for the two cases allows an easier comparison between the two technologies, and the presence of reheat for the GT24/26 renders the conditions for thermodynamic optimisation of the bottoming cycle similar for practical purposes (the temperature at the gas turbine exhaust is similar in the two cases).

In Table 2, the main thermodynamic parameters used for the HRSG are shown.

The maximum steam temperature at the exit of the superheater and reheater was fixed at 833

Table 2

HRSG and steam section basic parameters

\begin{tabular}{lll}
\hline Parameter & Symbol & Value \\
\hline Pinch point economizer temperature difference (K) & $\Delta T_{\mathrm{pp}}$ & 14 \\
Pinch point evaporator temperature difference (K) & $\Delta T_{\mathrm{pp}}$ & 20 \\
Evaporator subcooling (K) & $\Delta T_{\mathrm{ap}}$ & 8 \\
Superheater approach (K) & $\Delta T_{\mathrm{ap}}$ & 20 \\
Maximum steam temperature (K) & $T_{\text {max steam }}$ & 833 \\
Efficiency, HP steam turbine (\%) & $\eta_{\text {is }}$ & 88 \\
Efficiency, IP steam turbine (\%) & $\eta_{\text {is }}$ & 90 \\
Efficiency, LP steam turbine (\%) & $\eta_{\text {is }}$ & 90 \\
Condenser pressure (kPa) & $p_{\text {cond }}$ & $7(5,10)$ \\
Gas side pressure loss (kPa) & $\Delta p_{\text {tot }}$ & 5.6 \\
Efficiency of all heat exchangers (\%) & $\eta_{\text {ex }}$ & 99 \\
Efficiency of AC generators (\%) & $\eta_{\text {gen }}$ & 99 \\
\hline
\end{tabular}


$\mathrm{K}\left(560^{\circ} \mathrm{C}\right)$, even if the fuel (natural gas, treated as pure methane in the present simulation) would allow operation at larger temperatures without relevant problems of corrosion. Under these conditions, the HRSG operation with fuel oil burners for the stand alone operation of the bottomer cycle is possible.

The condenser pressure was fixed at a reference value of $7 \mathrm{kPa}$, typically corresponding to that achievable using a humid refrigeration tower in atmospheric reference conditions as the heat sink. Subsequently, the effects of a variation of this parameter were also analysed, assuming the values of $10 \mathrm{kPa}$ (dry refrigeration tower) and $5 \mathrm{kPa}$ (water refrigeration).

The pressure losses in the HRSG $(5.6 \mathrm{kPa})$ were considered as concentrated at the exit of the gas turbine, while those on the water/steam side in the heat exchangers were not considered (because of their limited influence and the approximate nature of their calculation).

\subsubsection{Generators}

For AC generators, a high value of efficiency was chosen $(99 \%)$, considering that no reduction gears between this component and the turbine shaft are needed for large size gas and steam turbines.

\subsubsection{Compressors}

For both plants, the compressors were simulated using the standard model of the multi-exit compressor. The polytropic efficiency was fixed at the value of $91.5 \%$.

\subsubsection{Combustor}

The combustion efficiency was fixed at $99 \%$, and the relative pressure loss is 0.05 of the entrance pressure. These values are again typical of large size gas turbines.

\subsubsection{Turbines}

Particular attention was paid to expansion in the turbines; this required splitting the expansion into several processes in order to account for different cooling methodologies which

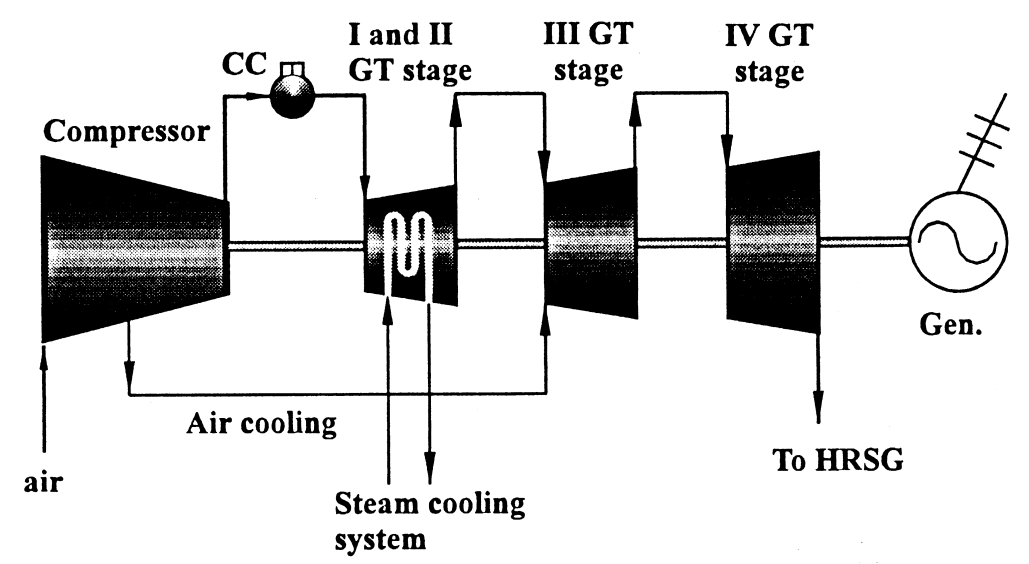

Fig. 4. Simulation scheme, LM9001H. 
entail different efficiencies of the expansion process (steam cooled; air cooled; no cooling last stage). The correct treatment of the cooled expansion has an important influence on the performance of the simple cycle and, consequently, also on that of the combined one. Referring to the structure of the cooled gas turbine model, the expansion was divided into several parts, with the aim of approaching the behaviour of the real process as closely as possible.

The schemes of the two turbines are shown in Figs. 4 and 5.

\section{Simulation process}

The simulation of both plants involved the following steps:

- thermodynamic simulation of the gas turbine operating in simple cycle

- insertion of the steam cycle and simulation of the combined cycle

- study of the optimal thermodynamic characteristics with particular reference to specific work and efficiency

- sensitivity analysis for the following parameters: $\mathrm{I}_{\max }, p_{\max }$ and $p_{\text {cond }}$.

\subsection{Combined cycle based on GT26 gas turbine}

It is useful to make some comments about the optimisation of the three pressure levels of the bottoming cycle. The third one was chosen coinciding with the maximum pressure allowed $p_{\mathrm{HP} \text {, opt }}=p_{\max }=150$ bars. This is not the optimum value, which would be found for larger pressures, beyond the current technological level; the 150 bars value was selected because it does not entail particular technological problems and, at the same time, is not too penalising from the point of view of performance. The other two pressure levels - intermediate and low - were chosen with the aim of optimising performance. The main results are summarised in Table 3.

In optimum conditions, which were determined by means of a sensitivity analysis for

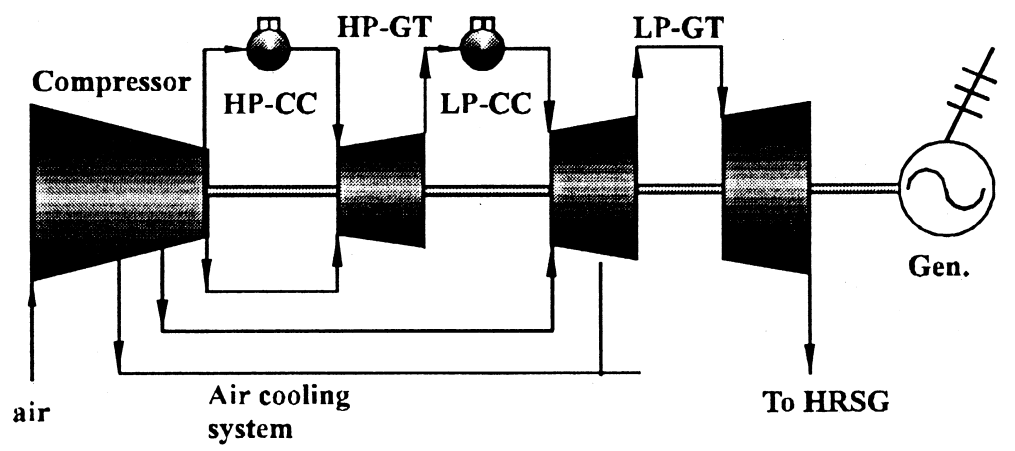

Fig. 5. Simulation scheme, GT26. 
Table 3

Results of simulation of the CC plant based on GT26 ( $\left.p_{\mathrm{HP}}=150 \mathrm{bar}\right)$

\begin{tabular}{|c|c|c|}
\hline Element & Parameter & Value \\
\hline \multirow[t]{5}{*}{ Gas turbine } & High pressure firing temperature, $T_{\mathrm{HP}, \max }(\mathrm{K})^{\mathrm{a}}$ & 1508 \\
\hline & Intermediate pressure firing temperature, $T_{\mathrm{IP}, \max }(\mathrm{K})^{\mathrm{a}}$ & 1508 \\
\hline & Flow rate, $m_{\text {out }}(\mathrm{kg} / \mathrm{s})$ & 545 \\
\hline & Power, $W(\mathrm{MW})$ & 241 \\
\hline & Specific work, $W_{\mathrm{s}}(\mathrm{kJ} / \mathrm{kg})$ & 434 \\
\hline \multirow[t]{9}{*}{ Steam turbine } & High pressure, $p_{\mathrm{HP}}$ (bar) ${ }^{\mathrm{a}}$ & 150 \\
\hline & Intermediate pressure, $p_{\mathrm{IP}, \text { opt }}(\mathrm{bar})$ & 35 \\
\hline & Low pressure, $p_{\mathrm{LP}, \text { opt }}(\mathrm{bar})$ & 2.9 \\
\hline & Condensation pressure, $p_{\text {cond }}(\mathrm{kPa})^{\mathrm{a}}$ & 7 \\
\hline & Flow rate of high pressure, $m_{\mathrm{HP}}(\mathrm{kg} / \mathrm{s})$ & 66.5 \\
\hline & Flow rate of intermediate pressure, $m_{\mathrm{IP}}(\mathrm{kg} / \mathrm{s})$ & 78.6 \\
\hline & Flow rate of low pressure, $m_{\mathrm{LP}}(\mathrm{kg} / \mathrm{s})$ & 89.2 \\
\hline & Power, $W(\mathrm{MW})$ & 125.6 \\
\hline & Specific work, $W_{\mathrm{s}}(\mathrm{kJ} / \mathrm{kg})$ & 228 \\
\hline \multirow[t]{3}{*}{ Boiler } & Maximum steam temperature, $T_{\max , \text { steam }}(\mathrm{K})$ & 833 \\
\hline & Gas temperature at the exit of the HRSG, $T_{\text {out }}(\mathrm{K})$ & 369 \\
\hline & HRSG heat duty (MW) & 371 \\
\hline \multirow[t]{3}{*}{ Overall performances } & $\mathrm{CC}$ power, $W_{\mathrm{el}}(\mathrm{MW})$ & 363 \\
\hline & CC specific work, $W_{\mathrm{s}, \text { el }}(\mathrm{kJ} / \mathrm{kg})$ & 654 \\
\hline & Efficiency of CC, $\eta_{\mathrm{el}}(\%)$ & 57.2 \\
\hline
\end{tabular}

${ }^{\text {a }}$ Fixed value.

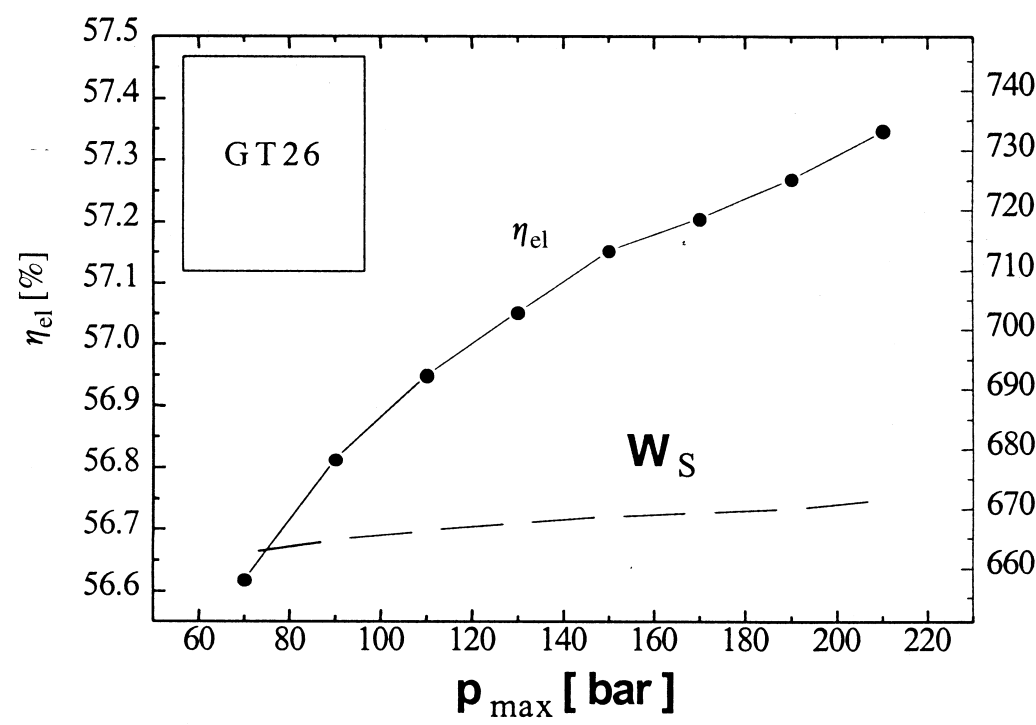

Fig. 6. Effects of $p_{\mathrm{HP}}$ on efficiency and specific work. 
different values of the three pressure levels, the value of the three level pressures are related by the following ratios: $p_{\mathrm{HP}}: p_{\mathrm{IP}}: p_{\mathrm{LP}}=52: 12: 1$. Several simulations verified that with variable $p_{\mathrm{HP}}$, optimum performances are reached for similar ratios. This allowed us to study the effects on efficiency and specific work only considering the high pressure. The results of this study are shown in Fig. 6.

As can be seen in this figure, the efficiency grows somewhat less than $1 \%$ passing from $p_{\mathrm{HP}}$ $=70$ to 210 bar (close to critical pressure), while the specific work remains almost unchanged. These values justify the assumed value for $p_{\mathrm{HP}}=150$ bars. In any case, beyond 120 bars, the efficiency is larger than $57 \%$. Consequently, simulation does not favour choosing values larger than 150 bars, because the modest improvement in performance would not compensate for the increased technical obstacles.

The next step in our study regards the influence of the maximum cycle temperature on the combined cycle performance. As the GT26 has a relatively low firing temperature in comparison with values typical of " $F$ " and " $G$ " generation turbines, only positive variations of $T_{\max }$ were considered. Fig. 7 shows the results obtained.

Instead of $p_{\mathrm{HP}}$, whose variation has, in practice, only influenced efficiency, the increase of $T_{\max }$ entails relevant effects also on the specific work for the GT26. If the typical values of the "F" generation turbines are considered $\left(T_{\max }=1508-1638 \mathrm{~K}\right)$, an increase in specific work of about $80 \mathrm{~kJ} / \mathrm{kg}$ can be achieved, while the efficiency reaches $58 \%$. The improvement in specific work is divided equally between the topping and bottoming cycles.

Consideration of a temperature increase of this size necessarily involves a redesign of many hot parts, including at least the cooling system of the first stage nozzles. In this case, it would be interesting to evaluate the beneficial effects achievable by cooling of the air cooling flow using an external heat exchanger, transferring heat to the steam coming from the bottoming cycle.

Brief reference is necessary here to the low value of the temperature of the exhaust gases at the exit of the HRSG. The value of $369 \mathrm{~K}\left(96^{\circ} \mathrm{C} / 205 \mathrm{~F}\right)$ is not a problem if the fuel is clean

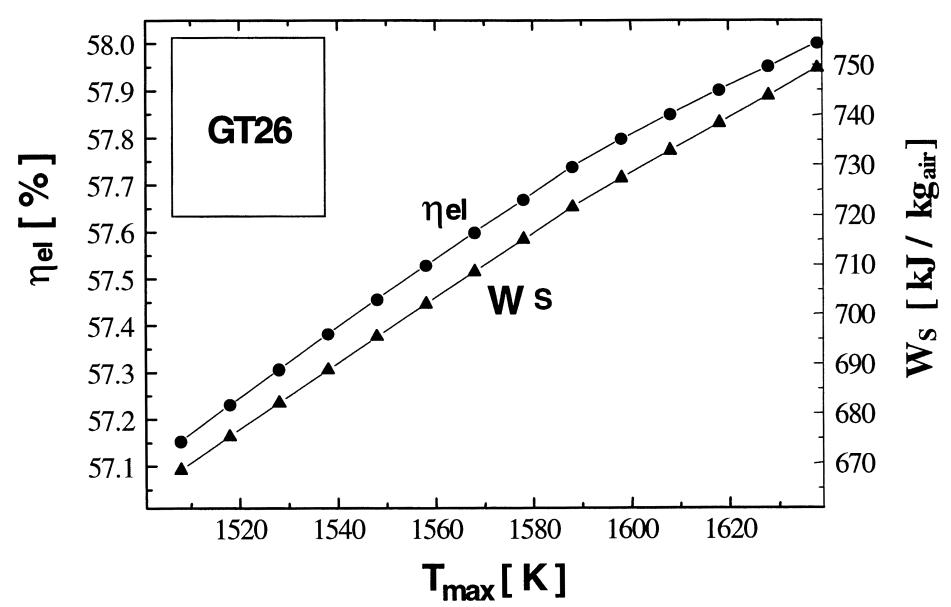

Fig. 7. Effects of firing temperature on efficiency and specific work. 
Table 4

Effect of saturation pressure at condenser (GT26-CC)

\begin{tabular}{llll}
\hline Saturation pressure $p_{\text {cond }}(\mathrm{kPa})$ & 5 & 7 & 10 \\
\hline Saturation temperature $\left(\mathrm{K} /{ }^{\circ} \mathrm{C}\right)$ & $306 / 33$ & $313 / 40$ & $319 / 46$ \\
$\mathrm{CC}$ efficiency $(\%)$ & 57.7 & 57.2 & 56.5 \\
$\mathrm{CC}$ specific work $(\mathrm{kJ} / \mathrm{kg})$ & 675 & 669 & 661 \\
\hline
\end{tabular}

natural gas, but the bottoming cycle can be operated, possibly also in stand alone mode, with a lower quality fuel.

All cases examined so far refer to a condenser pressure of $7 \mathrm{kPa}(1.015 \mathrm{psi})$. This pressure level corresponds to a saturation temperature of $313 \mathrm{~K}\left(40^{\circ} \mathrm{C} / 104 \mathrm{~F}\right)$, which can be reached with a humid type refrigeration tower. Simulations were also run with other values of this parameter, in particular, for $p_{\text {cond }}=10 \mathrm{kPa}(1.45 \mathrm{psi})$, corresponding to a temperature of 319 $\mathrm{K}\left(46^{\circ} \mathrm{C} / 115 \mathrm{~F}\right)$, obtainable with a dry refrigeration tower $)$ and $p_{\text {cond }}=5 \mathrm{kPa}(0.725 \mathrm{psi})$ $\left(T_{\text {cond }}=306 \mathrm{~K}\left(33^{\circ} \mathrm{C} / 91.4 \mathrm{~F}\right)\right.$, corresponding to an open loop sea water cooling system).

In Table 4, the results obtained are summarised. It is important to notice that this is not an off design analysis but a simple sensitivity analysis on the effects of different condenser operating conditions.

In conclusion, we can say that the three level pressure combined cycle with reheat and GT26 gas turbine allows one to obtain an efficiency greater then $57 \%$ and a specific work exceeding $670 \mathrm{~kJ} / \mathrm{kg}$. These performances are particularly attractive, because they are obtained using a machine that offers high reliability at limited investment costs.

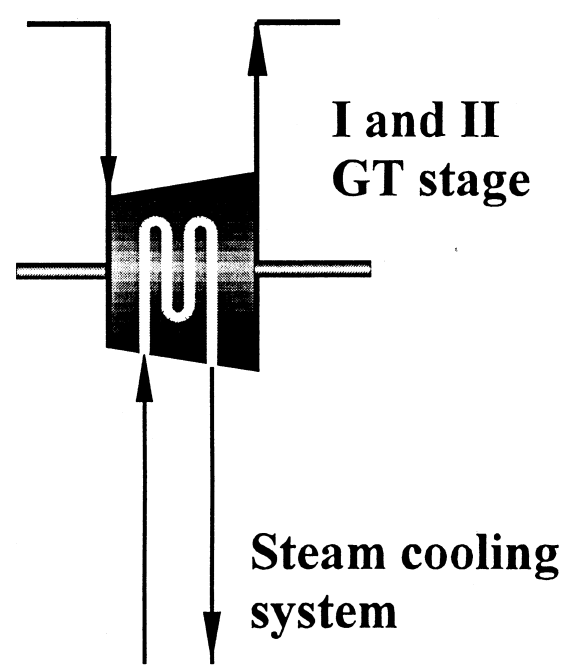

Fig. 8. Steam cooling path scheme in the GT. 
Table 5

Results of the CC plant simulation based on MS9001H ( $p_{\mathrm{PH}}=150$ bar $)$

\begin{tabular}{lll}
\hline Element & Parameter & Value \\
\hline Gas turbine & High pressure firing temperature, $\mathrm{TIT}_{\mathrm{HP}}(\mathrm{K})^{\mathrm{a}}$ & 1700 \\
& Flow rate, $m_{\text {out }}(\mathrm{kg} / \mathrm{s})$ & 685 \\
Steam turbine & Power, $W(\mathrm{MW})$ & 339 \\
& Specific work, $W_{\mathrm{s}}(\mathrm{kJ} / \mathrm{kg})$ & 506 \\
& High pressure, $p_{\mathrm{HP}}(\mathrm{bar})^{\mathrm{a}}$ & 150 \\
& Intermediate pressure, $p_{\mathrm{IP}, \text { opt }}(\mathrm{bar})$ & 40 \\
& Low pressure, $p_{\mathrm{LP}, \text { opt }}(\mathrm{bar})$ & 3.2 \\
& Condensation pressure, $p_{\mathrm{cond}}(\mathrm{kPa})^{\mathrm{a}}$ & 7 \\
& Flow rate of high pressure, $m_{\mathrm{HP}}(\mathrm{kg} / \mathrm{s})$ & 101.1 \\
& Flow rate of intermediate pressure, $m_{\mathrm{IP}}(\mathrm{kg} / \mathrm{s})$ & 110.7 \\
& Flow rate of low pressure, $m_{\mathrm{LP}}(\mathrm{kg} / \mathrm{s})$ & 121.6 \\
& Power, $W(\mathrm{MW})$ & 173 \\
Boiler & Specific work, $W_{\mathrm{s}}(\mathrm{kJ} / \mathrm{kg})$ & 259 \\
& Maximum steam temperature, $T_{\text {max, steam }}(\mathrm{K})$ & 833 \\
& Gas temperature at the exit of the HRSG, $T_{\text {out }}(\mathrm{K})$ & 365 \\
Overall performances & HRSG heat duty $(\mathrm{MW})$ & 410 \\
& CC power, $W_{\mathrm{el}}(\mathrm{MW})$ & 505 \\
& CC specific work, $W_{\mathrm{s}, \mathrm{el}}(\mathrm{kJ} / \mathrm{kg})$ & 754 \\
& CC efficiency, $\eta_{\mathrm{el}}(\%)$ & 60.1 \\
\hline
\end{tabular}

${ }^{\mathrm{a}}$ Fixed value.

\subsubsection{Combined cycle based on a MS9001H gas turbine}

All the simulations concerning the GT26 were also repeated for the MS9001H. The substantial difference consists in the splitting of the steam at the exit of the HP steam turbine into two flows: one directed towards the cooling system of the gas turbine, the other to the reheat section of the HRSG.

As the two flows must mix together after the steam reheater at about the same temperature level, and as enough data were not available from the manufacturer, we simulated, in series, the cooling steam path in the two stages of the gas turbine, as is shown in Fig. 8.

In particular, the flow coming out of the first stage cooling path goes into the second stage and, from this, into the IP steam turbine. Inside each stage, the steam is divided into the rotationary and stator nozzle cooling streams.

Table 6

Effects of condenser saturation pressure level (MS9001H-CC)

\begin{tabular}{llll}
\hline Saturation pressure, $p_{\text {cond }}(\mathrm{kPa})$ & 5 & 7 & 10 \\
\hline Saturation temperature, $\left(\mathrm{K} /{ }^{\circ} \mathrm{C}\right)$ & $306 / 33$ & $313 / 40$ & $319 / 46$ \\
$\mathrm{CC}$ efficiency $(\%)$ & 60.6 & 60.1 & 59.5 \\
$\mathrm{CC}$ specific work $(\mathrm{kJ} / \mathrm{kg})$ & 761 & 754 & 746 \\
\hline
\end{tabular}




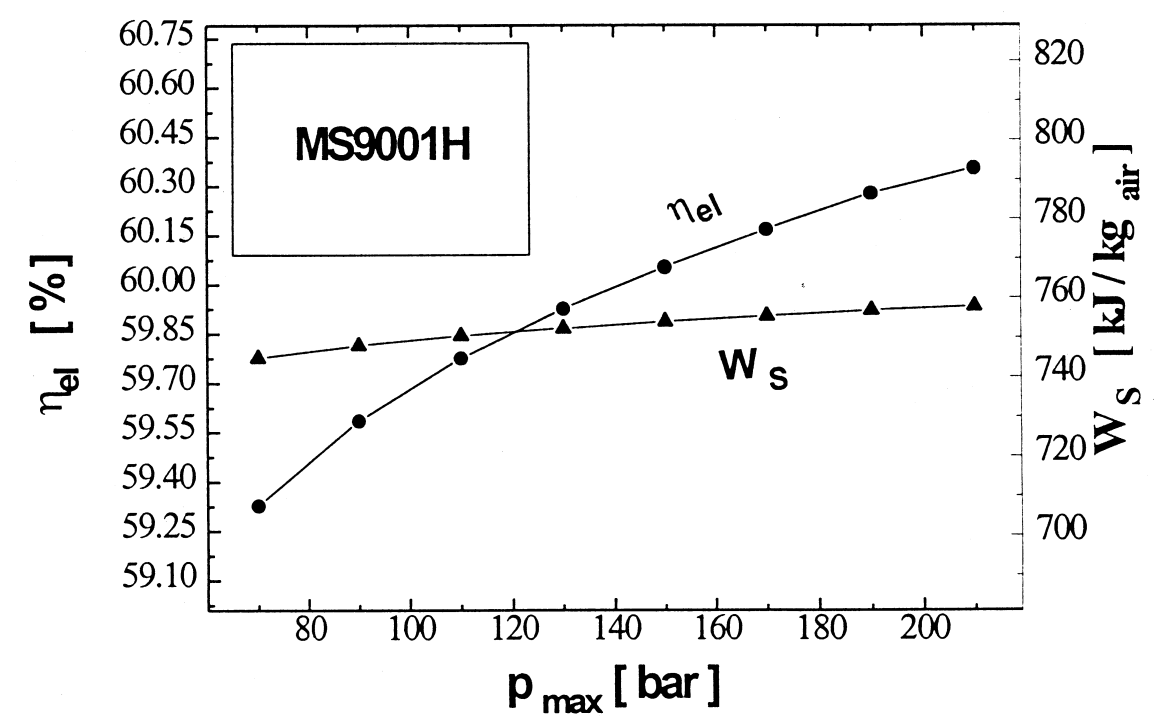

Fig. 9. Effects of $p_{\mathrm{HP}}$ on efficiency and specific work (MS9001H-CC).

The results obtained with the reference values of $T_{\max }, p_{\mathrm{HP}}$ and $p_{\text {cond }}$ are summarised in Table 5, whereas the effect of condenser pressure level are shown in Table 6.

The obtained values of efficiency and specific work are larger than those of the GT26. However, it must be stated that these results are probably affected by a relevant uncertainty level, as the simulation refers to projected data which are not directly confirmed by

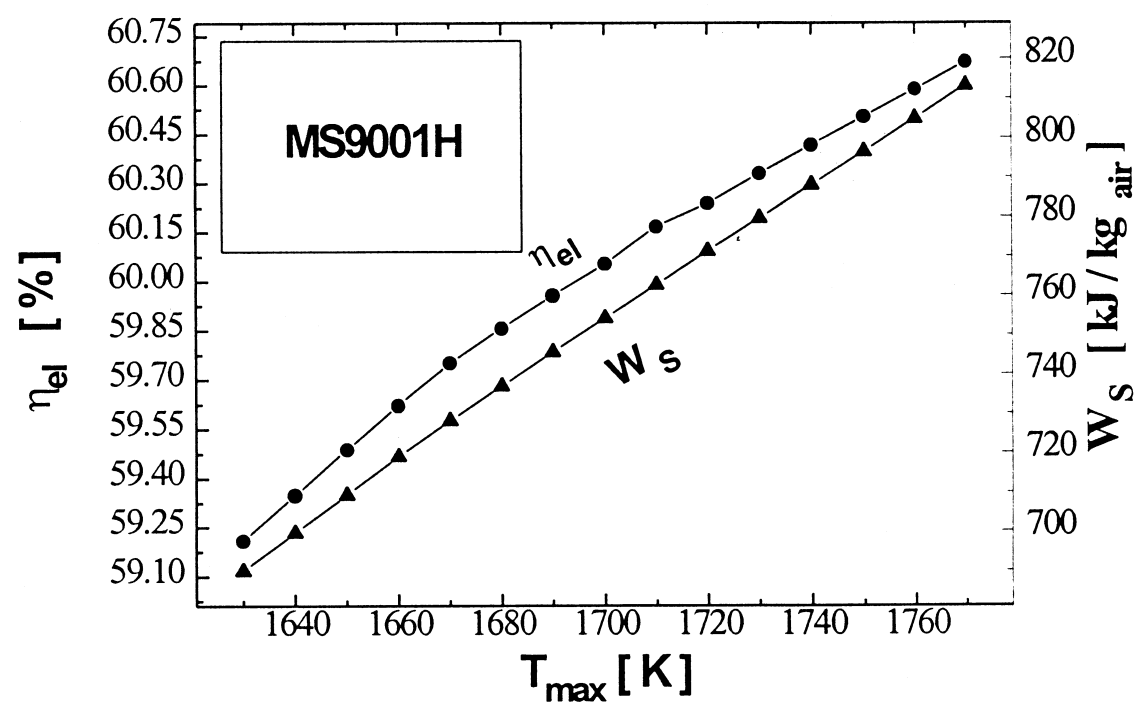

Fig. 10. Effects of firing temperature on efficiency and specific work (MS9001H-CC). 


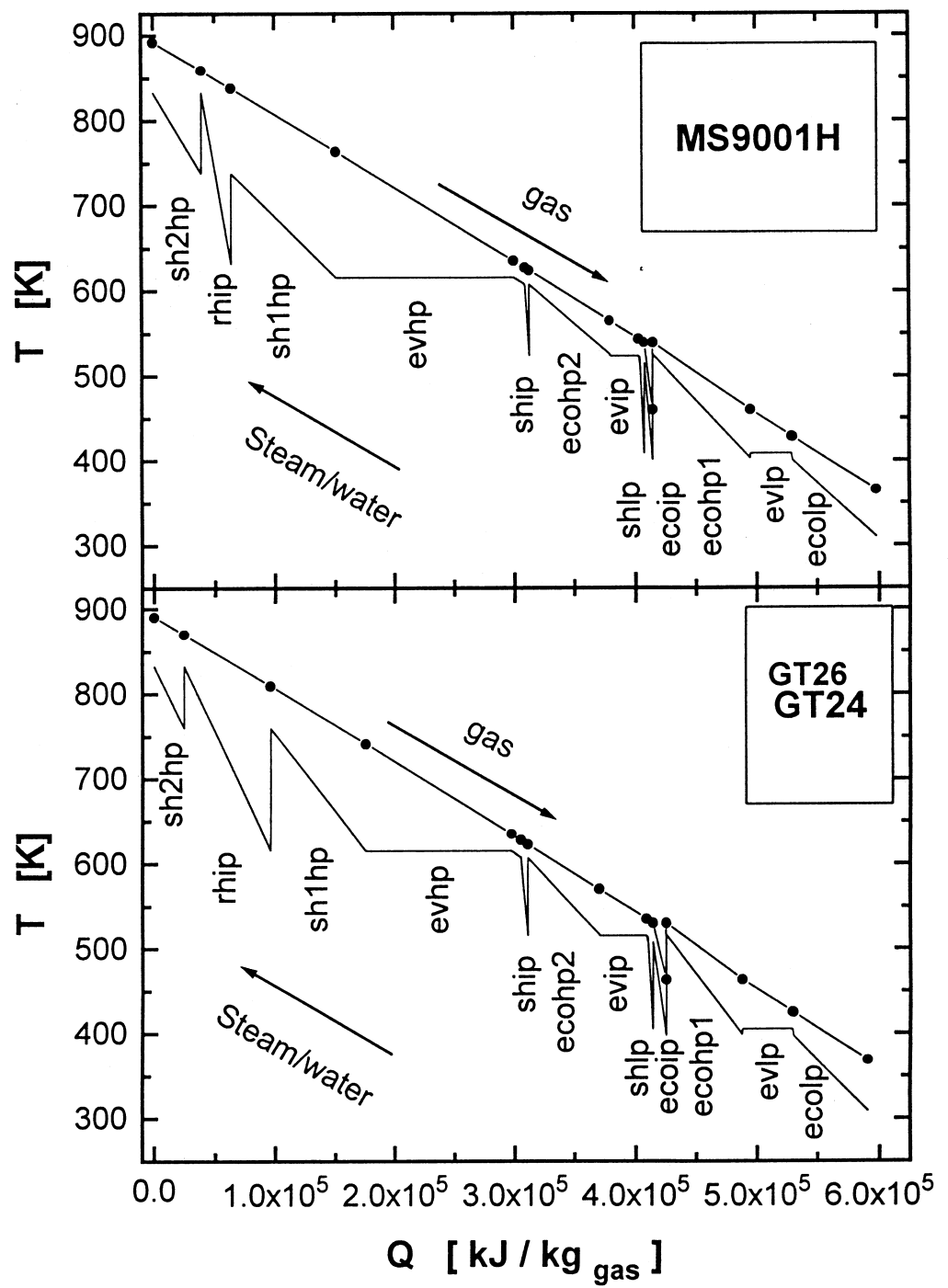

Fig. 11. Temperature profiles in the HRSG in optimum condition.

experimental tests. The same considerations as for the GT26 can be drawn about the effects produced by the variation of $p_{\mathrm{HP}}$ and $T_{\max }$, which are summarised in Figs. 9 and 10.

As the MS9001H already has a very high $T_{\max }$ level $(1700 \mathrm{~K})$, the influence of both an increase and a reduction of the firing temperature was studied. The simulations show that for $T_{\max }=1630 \mathrm{~K}$, the efficiency of the MS9001H is only $1 \%$ larger than that of the GT26 operating at the same temperature; on the other hand, the specific work can be substantially larger than that of the GT26 (exceeding $800 \mathrm{~kJ} / \mathrm{kg}$ for the gross output of gas and steam turbines), but this is true only if $T_{\max }$ levels larger than $1630 \mathrm{~K}$ are considered.

The values of the IP and LP of the HRSG for which we have the best performance (for 
fixed HP pressure level) are somewhat larger than those of the GT26. This can be explained by considering the fact that the " $\mathrm{H}$ " technology entails a higher average temperature level for the general heat transfer process. This is confirmed in the two diagrams of Fig. 11, in which the HRSG temperature profiles of the two flow streams (steam and gas) are given.

From the same figures, it can also be observed that the heat exchanged in the steam reheater (ReHeater at Intermediate Pressure, RHIP) is strongly reduced in the MS9001H, because a part of the steam flow to be reheated is sent to the gas turbine for cooling. On account of this, the effectiveness is hardly influenced by the value of the approach assigned in the first high pressure superheater (SH1HP). This suggests, as is indicated in Fig. 11, that this parameter can be left quite large, in comparison with the case of the GT26, with beneficial effects in terms of reduction of the heat transfer surface and without severe detrimental effects on the HRSG effectiveness.

\section{Conclusions}

The analysis of the simulation results, based only on the thermodynamic analysis, indicates that both "H" technology and reheat lead to a relevant increase of performance in terms of specific work and efficiency $(57.5 \%$ for the GT26 and $60 \%$ for the MS9001H). A supplementary simulation shows that the combination of the two technologies leads to an efficiency of about $62 \%$.

At the present level of this study, " $H$ " technology plants seem to allow one to reach efficiency levels which are presently beyond the limits of conventionally cooled gas turbine plants, but it also entails consistent technological obstacles which will certainly be reflected in higher plant investment costs. On the other hand, the GT26 uses consolidated technology with lower investment expenditure, but also a lower performance potential. So, it could be argued that the opportunity for utilisation of " $\mathrm{H}$ " technology is strictly dependent on the breakdown of the financial investment in terms of purchase and operation of the plant.

\section{Acknowledgements}

The authors would like to thank Prof. E. Carnevale for his valuable contributions to this study.

\section{References}

[1] ABB. GT24: Advanced cycle system. ABB Power Generation, Switzerland, Rep. No. PGT210393E, 1993.

[2] ABB. First GT24 will improve efficiency at Gilbert. ABB Power Generation, Switzerland, Rep. No. PGT 2145 94E, 1994.

[3] Carcasci C, Facchini B. A numerical method for power plant simulation. ASME J. of Energy Resources Technology 1996;118:36-43 (ASME Turbo Expo '95, Houston, TX, USA, June 5-8, 1995).

[4] Carcasci C, Facchini B, Biondi Bartolini J. Simulazione modulare di impianti di potenza e sistemi energetici. In: 
VIII Convegno Nazionale Tecnologie e Sistemi Energetici Complessi "Sergio Stecco", Bologna, 15-16 Giugno. 1995. p. 283-97.

[5] Carcasci C, Facchini B, Marra R. Modular approach to off-design gas turbine simulation: new prospects for reheat applications. ASME Turbo Expo '96, Paper 96-GT-395, Birmingham, UK, June 1996.

[6] Corman JC. H gas turbine combined cycle technology and development status. ASME Paper 96-GT-11, 1996. 